\title{
PENGARUH KEAKTIFAN SISWA DALAM MENGIKUTI BELA DIRI DAN PERHATIAN ORANG TUA TERHADAP PERILAKU BULLYING PADA SISWA KELAS VIII SMP NEGERI 2 KARANGREJO KABUPATEN MAGETAN TAHUN PELAJARAN 2013/2014
}

\author{
Fristiani Novita Sari * \\ Ibnu mahmudi **
}

\begin{abstract}
Abstrak
Penelitian ini untuk mengetahui: 1) pengaruh keaktifan siswa dalam mengikuti bela diri terhadap perilaku bullying. 2) pengaruh perhatian orang tua terhadap perilaku bullying. 3) pengaruh keaktifan siswa dalam mengikuti bela diri dan perhatian orang tua terhadap perilaku bullying

Penelitian dilaksanakan di SMP Negeri 2 Karangrejo Kabupaten Magetan tahun pelajaran 2013/2014. Populasi pada penelitian ini adalah seluruh siswa kelas VIII SMP Negeri 2 Karangrejo yang berjumlah 221 siswa. Pengambilan sampel dilakukan dengan cara sampling purposive. Jumlah anggota sampel sebanyak 44 siswa atau $20 \%$ dari jumlah populasi.

Hasil penelitian menunjukkan (1) pengaruh keaktifan siswa dalam mengikuti bela diri terhadap perilaku bullying siswa kelas VIII SMP Negeri 2 Karangrejo tahun pelajaran 2013/2014 memperoleh nilai $r_{\text {hitung }}=0,39>r_{\text {tabel }}=$ 0,297. (2) pengaruh perhatian orang tua terhadap perilaku bullying siswa kelas VIII SMP Negeri 2 Karangrejo tahun pelajaran 2013/2014, memperoleh nilai $r_{\text {hitung }}=0,63>r_{\text {tabel }}=0,297$. (3) pengaruh keaktifan siswa dalam mengikuti bela diri dan perhatian orang tua terhadap perilaku bullying siswa kelas VIII SMP Negeri 2 Karangrejo tahun pelajaran 2013/2014, memperoleh nilai $F_{\text {reg }}>F_{\text {tabel }}=$ $(14,96>1,684)$.

Berdasarkan hasil tersebut dapat disimpulkan bahwa: (1) Ada pengaruh keaktifan siswa dalam mengikuti bela diri terhadap perilaku bullying siswa kelas VIII SMP Negeri 2 Karangrejo tahun pelajaran 2013/2014. (2) Ada pengaruh perhatian orang tua terhadap perilaku bullying siswa kelas VIII SMP Negeri 2 Karangrejo tahun pelajaran 2013/2014, (3) Ada pengaruh keaktifan siswa dalam mengikuti bela diri dan perhatian orang tua terhadap perilaku bullying siswa kelas VIII SMP Negeri 2 Karangrejo tahun pelajaran 2013/2014. Saran, sekolah hendaknya melakukan evaluasi dan memonitor terhadap pelaksanaan tata tertib sekolah agar perilaku bullying di sekolah dapat di minimalisir atau bahkan dihilangkan di masa yang akan datang.
\end{abstract}

Kata Kunci : Keaktifan Siswa dalam Mengikuti Bela Diri, Perhatian Orang Tua, dan Perilaku Bullying

* Fristiani Novita Sari adalah Mahasiswa Program Studi Bimbingan dan Konseling Fakultas Ilmu Pendidikan IKIP PGRI Madiun.

** Ibnu Mahmudi adalah Dosen Program Studi Bimbingan dan Konseling Fakultas Ilmu Pendidikan IKIP PGRI Madiun. 


\section{A. PENDAHULUAN}

Berbagai fenomena sampai saat ini masih banyak dibicarakan oleh masyarakat yaitu tindak kekerasan yang dilakukan oleh para siswa. Kondisi tersebut dipengaruhi banyak faktor, menurut Andrew Mellor \& Ratna Djuwita (dalam Pony Retno Astuti, 2008: 50) bullying terjadi akibat faktor lingkungan, keluarga, sekolah, media, budaya, dan peer group. Lebih lanjut Komarudin Hidayat (2008: 50) tapi, bullying juga muncul oleh adanya pengaruh dari situasi politik dan ekonomi yang koruptif. Ida Novianti (2008: 4) menyebutkan bahwa beberapa faktor diyakini menjadi penyebab bullying. Keluarga, individual dan sekolah adalah beberapa hal diantaranya. Dari faktor-faktor tersebut maka salah satu faktor yang mempengaruhi perilaku bullying adalah kegiatan-kegiatan siswa selama berada di luar jam sekolah yaitu mengikuti kegiatan bela diri.

Bela diri adalah suatu akifitas gerak yang digunakan untuk membela diri dari serangan musuh. Siswa yang mengikuti bela diri diharapkan mampu menjadi pribadi yang tangguh, mampu melindungi dirinya sendiri, mampu mengendalikan diri dan menahan emosi. Disamping itu, bela diri juga merupakan sarana untuk meraih prestasi. Hal itu terlihat ketika dalam pertandingan bela diri, banyak sekali atlet yang tergabung dan setiap atlet yang mengikuti bersikap ramah, santun dan patuh pada setiap peraturan.

Fenomena di SMP Negeri 2 Karangrejo, banyak siswa yang mengikuti bela diri kemudian sering digunakan untuk pamer, menakut-nakuti siswa yang lain, bersikap arogan ketika jam pelajaran berlangsung. Disamping itu bela diri digunakan untuk ajang adu kuat, menekan siswa yang lemah, dan berkelahi antar siswa. Hal ini bertentangan dengan tujuan utama mengikuti bela diri.

Merujuk dari penjelasan sebelumnya yang menyebutkan bahwa salah satu faktor yang menyebabkan bullying adalah keluarga. Salah satu peran dari keluarga adalah memberikan perhatian kepada anak, hal ini dipersepsi berdasarkan pada bagaimana cara orang tua memperlakukan, mendidik dan 
membentuk karakter anak selama berada di rumah. Karena bagaimanapun sikap dan perbuatan siswa di sekolah, tetaplah pendidikan utama berasal dari lingkungan keluarga yaitu orang tua. Perhatian dari orang tua sangat penting sekali, dikarenakan orang tua akan lebih mengontrol dan mengawasi setiap aktivitas yang dilakukan oleh siswa agar tetap terarah pada pembentukan diri yang positif.

Hasil pengamatan yang dilakukan di SMP Negeri 2 Karangejo ketika peneliti melaksanakan Praktik Pengalaman Lapangan (PPL), banyak orang tua siswa yang bekerja sebagai buruh tani, merantau ke kota besar, dan menjadi Tenaga Kerja Indonesia (TKI) ke luar negeri, menyebabkan intensitas perhatian orang tua yang seharusnya diberikan kepada siswa menjadi berkurang. Hal tersebut menjadi salah satu hal yang menyebabkan siswa melanggar norma dan aturan sekolah, berkelahi, menyakiti orang lain dan juga penganiayaan. Perilaku-perilaku tersebut merupakan bentuk dari bullying. Sebagaimana dikemukakan oleh Ken Rigby (dalam Ponny Retno Astuti,2008: 3) menyatakan bullying adalah sebuah hasrat untuk menyakiti. Hasrat ini diperlihatkan kedalam aksi, menyebabkan seseorang menderita. Aksi ini dilakukan secara langsung oleh seseorang atau kelompok yang lebih kuat, tidak bertanggungjawab, biasanya berulang, dan dilakukan dengan perasaan senang.

Lebih lanjut berdasar pengamatan di SMP Negeri 2 Karangrejo, konselor menginformasikan bahwa di sekolah ini menunjukkan bahwa beberapa siswa terindikasi merupakan korban dan pelaku bullying, selain itu di setiap kelas terdapat kelompok-kelompok yang terindikasi sebagai pelaku bullying. Hal ini ditunjukkan dengan siswa menarik rambut teman, sedang pelaku bullying dilakukan oleh kelompok. Hampir semua siswa pelaku bullying mengikuti kegiatan bela diri, akan tetapi diduga kurang mendapat arahan dan perhatian yang maksimal dari pelatih dan orang tuanya tentang tujuan beladiri sehingga siswa tidak bisa mengarahkan dan mengekspresikan ketrampilan yang dimilikinya dari 
bela diri kearah yang positif. Pada umumnya siswa pelaku bullying memiliki ciri khas yaitu agresif yang tinggi dan rasa empati yang sangat kurang. Padahal sangat diharapkan sekali dengan adanya pendidikan di sekolah, maka siswa akan dapat berinteraksi sosial dengan siswa yang lain, menambah rasa solidaritas dan empati, saling menyayangi. Sehingga aktivitas belajar di sekolah menjadi aman dan nyaman.

Dari permasalahan tersebut maka peneliti ingin mengkaji lebih dalam lagi tentang pengaruh keaktifan siswa dalam mengikuti bela diri dan perhatian orang tua terhadap perilaku bullying, dengan demikian peneliti mengambil judul "Pengaruh Keaktifan Siswa Dalam Mengikuti Bela Diri Dan Perhatian Orang Tua Terhadap Perilaku Bullying Pada Siswa Kelas VIII SMP Negeri 2 Karangrejo Kabupaten Magetan Tahun Pelajaran 2013/2014. 1) Apakah ada pengaruh keaktifan siswa dalam mengikuti bela diri terhadap perilaku bullying pada siswa kelas VIII SMP Negeri 2 Karangrejo Kabupaten Magetan Tahun Ajaran 2013/2014? 2) Apakah ada pengaruh perhatian orang tua terhadap perilaku bullying pada siswa kelas VIII SMP Negeri 2 Karangrejo Kabupaten Magetan Tahun Ajaran 2013/2014? 3) Apakah ada pengaruh keaktifan siswa dalam mengikuti bela diri dan perhatian orang tua terhadap perilaku bullying pada siswa kelas VIII SMP Negeri 2 Karangrejo Kabupaten Magetan Tahun Ajaran 2013/2014?

Berdasarkan perumusan masalah tersebut maka tujuan yang ingin dicapai dalam penelitian ini adalah 1) untuk mengetahui pengaruh kekaktifan siswa dalam mengikuti bela diri terhadap perilaku bullying pada siswa kelas VIII SMP Negeri 2 Karangrejo tahun pelajaran 2013/2014, 2) untuk mengetahui pengaruh perhatian orang tua terhadap perilaku bullying pada siswa kelas VIII SMP Negeri 2 Karangrejo tahun pelajaran 2013/2014, 3) untuk mengetahui pengaruh secara simultan keaktifan siswa dalam mengikuti bela diri dan perhatian orang tua terhadap perilaku bullying pada siswa kelas VIII SMP Negeri 2 Karangrejo tahun pelajaran 2013/2014. 


\section{B. KAJIAN PUSTAKA}

\section{Keaktifan Siswa dalam Mengikuti Bela Diri}

Kamus besar bahasa Indonesia (2008: 31) menjelaskan bahwa "keaktifan adalah kegiatan atau kesibukan."

Arthur S. Reber \& Emily S. Reber (2010: 12) menyebutkan "activity (aktivitas atau kegiatan) sebuah istilah yang diaplikasikan dengan baik sebagai sinonim bagi tindakan, gerakan, perilaku, proses mental, fungsi- fungsi fisiologis, dsb."

M. Mulyono (dalam Taofik, 2010: 11) menyatakan bahwa "keaktifan adalah kegiatan atau aktifitas dan segala sesuatu yang dilakukan atau kegiatan-kegiatan yang terjadi baik secara fisik maupun non fisik."

Ensiklopedia bebas Wikipedia Indonesia (dalam Lia Octavia 2009: 3) menyatakan bahwa "seni bela diri merupakan satu kesenian yang timbul sebagai cara seseorang itu mempertahankan diri.

Nur Dyah Naharsari (2008: 9) "bela diri ... mempunyai unsur seni dan beladiri yang di dalamnya terdapat unsur pengembangan keterampilan, sikap, kepribadian, dan rasa kebangsaan, yang sangat berguna untuk membentuk manusia seutuhnya (sehat jasmani maupun rohani)."

Rudy Mulyono (2008: 13) "bela diri dasar adalah seni bela diri yang berupa teknik-teknik gerakan dan menyalurkan tenaga yang sifatnya sebagai dasar guna membela atau melindungi diri dari serangan lawan, dan untuk melakukan serangan balik."

Berdasarkan uraian di atas maka peneliti berasumsi bahwa keaktifan siswa dalam mengikuti bela diri adalah keseringan siswa dalam melakukan teknik dan gerakan-gerakan yang dapat digunakan untuk melindungi diri dari serangan musuh.

\section{Perhatian Orang Tua}

Siska Eko Mawarsih (2013: 5) berpendapat bahwa "perhatian orang tua adalah suatu aktivitas yang tertuju pada suatu hal dalam hal 
ini adalah aktivitas anak dalam belajar yang dilakukan oleh orang tuanya."

Darwin Bangun (2008: 78) berpendapat bahwa "perhatian orang tua adalah pemusatan tenaga psikis yang berupa pengamatan atau pengawasan yang dilakukan oleh orang tua terhadap semua aktivitas yang dilakukan oleh anaknya secara terus menerus agar apa yang diinginkan dapat tercapai, atau banyak sedikitnya kesadaran yang menyertai suatu aktivitas yang dilakukan.”

Berdasar pendapat di atas maka yang dimaksud dengan perhatian orang tua adalah segala aktivitas yang dilakukan orang tua yang bertujuan memusatkan tenaga mental dan psikis yang berfokus terhadap keluarganya dan memberikan bimbingan yang positif terhadap anaknya.

\section{Perilaku Bullying}

Ratna Yudhawati dan Dony Haryanto (2011: 13) "Perilaku adalah sesuatu yang bisa diamati alat indera sebagai hasil dari interaksi dengan lingkungannya."

Bimo Walgito (2004: 10) menyatakan bahwa "Perilaku atau aktivitas-aktivitas itu merupakan manifestasi kehidupan psikis."

Waston (dalam Ratna Yudhawati \& Dony Haryanto,2011: 3) "Perilaku manusia adalah hasil belajar sehingga unsur lingkungan sangat penting.

Steve Wharton (2005: 7) 'Definisi kata kerja 'to bully' dalam Oxford English Dictionary adalah tindakan untuk menimbulkan rasa sakit atau menyakiti orang lain untuk kepentingan sendiri."

Menurut Ken Rigby (dalam Ponny Retno Astuti,2008: 3) "Bullying adalah sebuah hasrat untuk menyakiti. Hasrat ini diperlihatkan ke dalam aksi, menyebabkan seseorang menderita. Aksi ini dilakukan secara langsung oleh seseorang atau kelompok yang 
lebih kuat, tidak bertanggung jawab, biasanya berulang, dan dilakukan dengan perasaan senang.

Yoli Hemdi (2010: 3) menyatakan bahwa "bullying adalah perbuatan menyakiti sesama teman."

Bertolak dari pengertian perilaku bullying di atas, maka dapat diartikan bahwa bullying adalah suatu tindakan verbal atau fisik yang dilakukan oleh seseorang atau kelompok untuk menyakiti orang yang lebih lemah.

\section{METODE PENELITIAN}

Desain Penelitian yang digunakan adalah desain korelasi ex post facto. Suharsimi Arikunto (2010: 17) menyatakan bahwa ex post facto yaitu penelitian tentang variabel yang kejadiannya sudah terjadi sebelum penelitian dilaksanakan atau bisa dikatakan suatu penelitian ilmiah yang penelitinya tidak dapat secara langsung memanipulasi dan mengendalikan satu atau lebih variabel bebas serta mengamati variabel terikat untuk melihat perbedaan yang sesuai dengan manipulasi variabel-variabel tersebut.

Desain ini menggambarkan pengaruh keaktifan siswa dalam mengikuti bela diri dan perhatian orang tua terhadap perilaku bullying .

Penelitian dilaksanakan di SMP Negeri 2 Karangrejo Kabupaten Magetan yang beralamatkan di J1. Raya Karangrejo, Kecamatan Karangrejo, Kabupaten Magetan.

Sugiyono (2010: 117) menyatakan bahwa "Populasi adalah wilayah generalisasi yang terdiri atas: obyek/subyek yang mempunyai kualitas dan karakteristik tertentu yang ditetapkan oleh peneliti untuk dipelajari dan kemudian dibuat simpulannya."

Populasi dalam penelitian ini adalah siswa kelas VIII SMP Negeri 2 Karangrejo tahun pelajaran 2013/2014 dengan jumlah siswa sebanyak 221 siswa.

Teknik yang digunakan untuk mengambil sampel adalah menggunakan teknik Sampling Purposive. Sugiyono (2010: 124) menyatakan bahwa sampling purposive adalah teknik penentuan sampel dengan 
pertimbangan tertentu. Misalnya akan melakukan penelitian tentang kualitas makanan, maka sampel sumber datanya adalah orang yang ahli makanan, atau penelitian tentang kondisi politik di suatu daerah, maka sampel sumber datanya adalah orang yang ahli politik. Begitu juga dengan kriteria sampel penelitian ini adalah siswa yang aktif mengikuti bela diri. Dari populasi yang berjumlah 221 siswa, maka pengambilan sampel $20 \%$ yaitu 44 siswa.

Teknik pengumpulan data dalam penelitian ini menggunakan teknik angket. Suharsimi Arikunto (2010: 194) menjelaskan angket adalah sejumlah pertanyaan tertulis yang digunakan untuk memperoleh informasi dari responden dalam arti laporan tentang pribadinya, atau hal-hal yang di ketahui. Angket ini digunakan untuk mengumpulkn data variabel keaktifan siswa dalam mengikuti bela diri, perhatian orangtua, dan perilaku bullying.

Angket disusun oleh peneliti dalam bentuk pilihan ganda dengan empat alternatif jawaban yaitu: (a) selalu, (b) sering, (c) kadang-kadang, (d) tidak pernah. Karena pertanyaan dalam bentuk pilihan ganda, maka angket ini termasuk tertutup sehingga alternatif pilhan jawabannya telah diatur dan ditentukan oleh peneliti dan siswa tinggal memilih jawaban yang sesuai dengan keadaan dirinya.

Untuk pengujian ini digunakan rumus korelasi product moment dengan angka kasar sebagaimana yang dikemukakan oleh Suharsimi Arikunto (2002: 138) seperti berikut:

$$
r_{X Y}=\frac{N \Sigma X Y-(\Sigma X)(\Sigma Y)}{\sqrt{\left\{N \Sigma X^{2}-(\Sigma X)^{2}\right\}\left\{N \Sigma Y^{2}-(\Sigma Y)^{2}\right\}}}
$$

Keterangan:

$$
\begin{aligned}
& r_{X Y}=\text { Koefisien korelasi variabel } \\
& \mathrm{N}=\text { Jumlah sampel } \\
& \mathrm{X}=\text { Skor item } \\
& \mathrm{Y}=\text { Skor total }
\end{aligned}
$$


a) Uji Reliabilitas Instrumen

Uji reliabilitas dalam penelitian ini dilakukan dengan menggunakan rumus Alpha. Penggunaaan rumus ini didasarkan pada alasan karena skor yang diperoleh bukan 1 dan 0 , tetapi 1 sampai dengan 4.

Rumus yang digunakan adalah:

$$
r_{11}=\left[\frac{k}{k-1}\right]\left[1-\frac{\sum \sigma_{b}^{2}}{\sigma_{t}^{2}}\right]
$$

(Suharsimi Arikunto, 2010: 239)

Keterangan :

$$
\begin{array}{rlr}
\boldsymbol{r}_{1}= & \text { reliabilitas instrumen } \\
\mathrm{k}= & \text { banyaknya butir pertanyaan } \\
\sum \sigma_{b^{2}}= & \text { jumlah varians butir } \\
\sigma_{t}^{2}= & \text { varians total }
\end{array}
$$

Instrumen dikatakan reliabel harus memenuhi indikator sebagai berikut:

1) Instrumen dapat dipercaya untuk digunakan sebagai alat pengumpul data karena instrumen tersebut sudah baik.

2) Instrumen yang baik tidak akan bersifat tendensius mengarahkan responden untuk memilih jawaban-jawaban tersebut.

3) Instrument yang baik mampu mengungkap data yang dapat dipercaya.

4) Datanya memang benar sesuai dengan kenyataannya, maka berapa kali diambil atau diungkapkan hasilnya akan tetap sama. 
Rumus varian butir dan varian total adalah sebagai berikut :

Varians butir

$$
\sigma_{b^{2}}=\frac{\sum X^{2}-\frac{\left(\sum X\right)^{2}}{n}}{n}
$$

Varians total

$$
\sigma_{t_{2}}=\frac{\sum Y^{2}-\frac{\left(\sum Y\right)^{2}}{n}}{n}
$$

Keterangan :

$$
\begin{array}{lll}
\sigma_{b^{2}} & = & \text { Varians butir } \\
\sigma_{t^{2}} & = & \text { Varians total } \\
\mathrm{X} & = & \text { Skor butir } \\
\mathrm{Y} & = & \text { Skor total } \\
\mathrm{n} & = & \text { Jumlah subyek }
\end{array}
$$

Kriteria penyajian jika $r$ hitung $>r$ tabel maka item dinyatakan reliabel Data penelitian ini dianalisis dengan beberapa teknik statistik yaitu:

1. Analisis data tentang pengaruh keaktifan siswa dalam mengikuti bela diri terhadap perilaku bullying pada siswa kelas VIII SMP Negeri 2 Karangrejo tahun pelajaran 2013/2014

2. Analisis data tentang perhatian orang tua terhadap perilaku bullying pada siswa kelas VIII SMP Negeri 2 Karangrejo tahun pelajaran 2013/2014

3. Analisis data tentang pengaruh keaktifan siswa dalam mengikuti bela diri dan perhatian orang tua terhadap perilaku bullying pada siswa kelas VIII SMP Negeri 2 Karangrejo tahun pelajaran 2013/2014 menggunakan 
teknik statistik yaitu dengan rumus "regresi dua predictor". Rumus bangun “Analisis Regresi Linier: Dua-Prediktor” sebagai berikut:

Koefisien korelasi antara kriterium $\mathrm{Y}$ dengan $\mathrm{X}_{1}$ dan $\mathrm{X}_{2}$ dapat diperoleh dari rumus :

$R_{y(1,2)}=\frac{\sqrt{a_{1} \sum x_{1} y+a_{2} \sum x_{2} y}}{\sum y^{2}}$

(Riduwan, M.B.A, 2009: 285)

Keterangan:

$$
\begin{array}{ll}
R_{y(1,2)} & =\text { Koefisien korelasi antara Y dengan XI dan X2 } \\
a_{1} & =\text { Koefisien predictor X1 } \\
a_{2} & =\text { Koefisien predictor X2 } \\
\sum x_{1} y & =\text { Jumlah produk antara X1 dan Y } \\
\sum x_{2} y & =\text { Jumlah produk antara X2 dan Y } \\
\sum y^{2} & =\text { Jumlah kuadrat kriterium Y }
\end{array}
$$

Untuk menguji keberartian koefesien regresi secara keseluruhan digunakan uji $\mathrm{F}$ dengan rumus :

$$
\begin{aligned}
& \qquad F_{r e g}=\frac{R^{2}(N-m-1)}{m\left(1-R^{2}\right)} \\
& \text { Keterangan: } \\
& \mathrm{F}_{\text {reg }} \text { : Harga F garis regresi } \\
& \mathrm{N} \quad \text { : Cacah Kasus } \\
& \mathrm{M} \text { : Cacah Prediktor } \\
& R \quad \text { : Koefisien korelasi antara kriterium dengan prediktor-prediktor }
\end{aligned}
$$




\section{HASIL PENELITIAN}

\section{Deskripsi Data}

a. Deskripsi Data Keaktifan Siswa dalam Mengikuti Bela Diri

Berdasarkan penelitian angket dengan $\mathrm{N}$ sebanyak 44, rentang 50-77 diperoleh perhitungan : Mean $(M)=64,1$, Median $(\mathrm{Me})=58,5$, Modus $(\mathrm{Mo})=43,3$, Standar deviasi $(\mathrm{SD})=48,27$, Skor maksimal 77 dan skor minimal 50

b. Deskripsi Data Perhatian Orang Tua

Berdasarkan penelitian angket dengan $\mathrm{N}$ sebanyak 44, rentang 32-71 diperoleh perhitungan : Mean $(\mathrm{M})=57,18$, Median $(\mathrm{Me})=$ 41,52, Modus $(\mathrm{Mo})=10,16$, Standar deviasi $(\mathrm{SD})=48,16$, Skor maksimal 71 dan skor minimal 32

c. Deskripsi Data Perilaku Bullying

Berdasarkan hasil angket yang telah dianalisis dengan $\mathrm{N}$ sebanyak 44, rentang 41-71 diperoleh perhitungan: Mean $(\mathrm{M})=54,3$, Median $(\mathrm{Me})=50,1$, Modus $(\mathrm{Mo})=36,3$, Standar deviasi $(\mathrm{SD})=$ 35,08, Skor maksimal 71 dan skor minimal 41

\section{Hasil Analisis Data}

Berdasarkan analisis data di atas maka diperoleh hasil sebagai berikut:

a) Hasil analisis data tentang pengaruh keaktifan siswa dalam mengikuti bela diri $\left(\mathrm{X}_{1}\right)$ terhadap perilaku bullying $(\mathrm{Y})$, menunjukkan $r_{\text {hitung }}=$ 0,39 dan $r_{\text {tabel }}=0,297$ dengan taraf signifikan 5\% dan $\mathrm{N}$ sebanyak 44 setelah dikonsultasikan dengan $r_{\text {tabel }}$, untuk mengetahui signifikan atau tidak signifikan, maka harga $r_{\text {hitung }}=0,39>r_{\text {tabel }}=0,297$. Ini berarti Hipotesis diterima, dengan demikian ada pengaruh keaktifan siswa dalam mengikuti bela diri $\left(\mathrm{X}_{1}\right)$ terhadap perilaku bullying $(\mathrm{Y})$.

b) Hasil analisis data tentang pengaruh perhatian orang tua $\left(X_{2}\right)$ terhadap perilaku bullying (Y), menunjukkan $r_{\text {hitung }}=0,63$ dan $r_{\text {tabel }}=0,297$ dengan taraf signifikan 5\% dan N sebanyak 44 setelah dikonsultasikan dengan $r_{\text {tabel }}$, untuk mengetahui signifikan atau tidak signifikan, maka 
harga $r_{\text {hitung }}=0,63>r_{\text {tabel }}=0,297$. Ini berarti Hipotesis diterima, dengan demikian ada pengaruh antara perhatian orang tua $\left(\mathrm{X}_{2}\right)$ terhadap perilaku bullying (Y)

c) Hasil analisis data tentang pengaruh keaktifan siswa dalam megikuti bela diri $\left(\mathrm{X}_{1}\right)$, dan perhatian orang tua $\left(\mathrm{X}_{2}\right)$ terhadap perilaku bullying (Y), menggunakan analisis regresi dua prediktor, diperoleh koefisien kriterium $\mathrm{Y}$ dengan prediktor $\mathrm{X}_{1}$ dan $\mathrm{X}_{2}$ menunjukan $r_{\text {hitung }}=14,96$ dikonsultasikan dengan $r_{\text {tabel }}$ dengan taraf signifikan 5\% diketahui $r_{\text {tabel }}=1,684$. Jadi $F_{\text {reg }}$ lebih besar dibandingkan dengan $F_{\text {tabel }}$, ini berarti Hipotesis diterima. Dengan demikian ada pengaruh yang signifikan dari keaktifan siswa dalam mengikuti bela diri $\left(X_{1}\right)$ dan perhatian orang tua $\left(\mathrm{X}_{2}\right)$ terhadap perilaku bullying $(\mathrm{Y})$.

d) Dengan demikian dari hasil penelitian memberikan sumbangan efektifitas keaktifan siswa dalam mengikuti bela diri $\left(\mathrm{X}_{1}\right)$ terhadap perilaku bullying $(\mathrm{Y})$ sebesar $9 \%$, dan perhatian orang tua $\left(\mathrm{X}_{2}\right)$ terhadap (Y) sebesar 31\%.

\section{E. SIMPULAN DAN SARAN}

\section{Simpulan}

Berdasarkan data hasil penelitian maka dikemukakan simpulan sebagai berikut :

a. Ada pengaruh keaktifan siswa dalam mengikuti bela diri terhadap perilaku bullying siswa kelas VIII SMP Negeri 2 Karangrejo Tahun Pelajaran 2013/2014.

b. Ada pengaruh perhatian orang tua terhadap perilaku bullying siswa kelas VIII SMP Negeri 2 Karangrejo Tahun Pelajaran 2013/2014.

c. Ada pengaruh keaktifan siswa dalam mengikuti bela diri dan perhatian orang tua terhadap perilaku bullying siswa kelas VIII SMP Negeri 2 Karangrejo Tahun Pelajaran 2013/2014. 


\section{Saran}

Berdasarkan hasil penelitian, maka dapat dikemukakan saran - saran sebagai berikut :

a. Bagi sekolah

Sekolah hendaknya perlu melakukan evaluasi dan memonitor pelaksanaan tata tertib sekolah agar perilaku bullying di sekolah dapat di minimalisir atau bahkan dihilangkan di masa yang akan datang.

b. Bagi Guru BK di sekolah

Guru BK/Konselor di sekolah hendaknya lebih tanggap terhadap perilaku siswa yang mengarah pada tindakan bullying dan memberikan layanan bimbingan konseling yang baik pada siswa sehingga siswa tidak melakukan tindakan bullying terhadap siswa yang lain.

c. Bagi orang tua

Orang tua hendaknya mengawasi aktivitas dan memberikan pengertian kepada anak agar tidak melakukan perilaku bullying.

d. Bagi Siswa

Siswa hendaknya lebih memanfaatkan ketrampilan bela diri yang dimiliki untuk berprestasi dan menjalin komunikasi yang baik dengan orang tua agar tidak terpengaruh pada perilaku bullying. 


\section{DAFTAR PUSTAKA}

Abu Ahmadi. 2009. Psikologi Umum. Jakarta: Rineka Cipta.

Achmad Kabain. 2010. Peran Keluarga, Guru, dan Sekolah Menyelamatkan Anak dari Pengaruh Napza. Semarang: PT Bengawan Ilmu.

Angger Pangreksa. 2011. Buku Pintar Bela Diri Silat Listrik. Yogyakarta: IN AzNa Books.

Arthur S. Reber \& Emily S. Reber. 2010. Kamus Psikologi . Yogyakarta: Pustaka

Belajar.

Bimo Walgito. 2004. Pengantar Psikologi Umum. Yogyakarta: ANDI.

Coloroso, Barbara. 2007. Stop Bullying! Memutus Rantai Kekerasan Anak dari Prasekolah Hingga SMU. Jakarta: PT Serambi Ilmu Semesta.

Darwin Bangun. 2008. Hubungan Persepsi Siswa Tentang Perhatian Orang Tua, Kelengkapan Fasilitas Belajar, dan Penggunaan Waktu Belajar di Rumah dengan Prestasi Belajar Ekonomi. Jurnal Ekonomi \& Pendidikan, Vol. 5. (http://journal.uny.ac.id/index.php/jep/article/viewFile/604/461, diakses 21 Nopember 2013).

Dendy Sugono. 2008. Kamus Besar Bahasa Indonesia. Jakarta: PT Gramedia Pustaka Umum.

Ida Novianti. 2008. Fenomena Kekerasan di Lingkungan Pendidikan. Jurnal $\begin{array}{llll}\text { Pemikiran Alternatif } & \text { Pendidikan, } & \text { Vol. }\end{array}$ (http://ejournal.stainpurwokerto.ac.id/index.php/insania/article/view/2008, diakses 21 Nopember 2013).

Imam Muhajirin \& Ibadullah Malawi. 2009. Penelitian Pendidikan. Madiun.

Jalaluddin Rakhmat. 2005. Psikologi Komunikasi. Bandung:PT Remaja Rosdakarya.

Joko Pamungkas. 2012. Panduan Lengkap Bela Diri dengan Tenaga Dalam. Yogyakarta : Araska.

Joko Susanta \& Sumaryati. 2013. Strategi Orang Tua dalam Menanamkan Sikap Tanggung Jawab Anak di Dusun Seropan I. Jurnal Citizenship. Vol. 2 (http://journal.uad.ac.id/index.php/Citizenship/article/download/1473/834, diakses 22 Januari 2013).

Kompas. 23 Desember, 2014. Pengertian Arti Dari Makna Orang Tua, hlm. 1 Lia Oktavia. 2009. Bela Diri For Muslimah. Jakarta: PT Lingkar Pena Kreativa.

Muhammad Muhyi Faruq. 2009. Meningkatkan Kebugaran Jasmani melalui Permainan dan Olahraga Pencak Silat. Surabaya: PT Gramedia Widiasarana Indonesia.

Nur Dyah Naharsari. 2008. Olahraga Pencak Silat. Jakarta: Ganeca Exact.

Ponny Retno Astuti. 2008. Meredam Bullying.Jakarta: PT Gramedia Widiasarana Indonesia.

Rani Febriany \&Yusri.2013. Hubungan Perhatian Orangtua Dengan MotivasiBelajar Siswa Dalam Mengerjakan Tugas-Tugas Sekolah. Jurnal IlmiahKonseling, Vol. 2. https://www.google.com/search?q=Rani+Febrianty+dan+Yusri+Jurnal+ilmi ah+konseling\&ie $=$ utf $-8 \&$ oe $=$ utf $-8 \&$ aq $=$ t\&rls=org. mozilla:enUS:official\&client=firefoxa\#q=Rani+Febrianty+dan+Yusri+Jurnal+ilmiah+ 
konseling+perhatian+orang+tua\&rls=org.mozilla:en-US:official, diakses 21

Nopember 2013)

Ratna Yudhawati,Dany Haryanto. 2011. Teori-Teori Dasar Psikologi Pendidikan. Jakarta: PT.Prestasi Pustakaraya.

Riduwan, M. B. A .2009. Pengatar Statistika Sosial. Bandung: Alfabeta.

Rudy Mulyono. 2008. Bela Diri Praktis untuk Wanita. Yogyakarta: Media

Pressindo.

Santrock, John W. 2007. Perkembangan Anak. Edisi Kesebelas. Jakarta:

Erlangga. 2007. Remaja Edisi Kesebelas Jilid 2. Jakarta: Erlangga. 2008. Psikologi Pendidikan. Jakarta: Kencana.

2011. Masa Perkembangan Anak Children. Edisi 11 Buku 1. Jakarta:

Salemba Humanika.

Singgih D.Gunarsa.2004.Psikologi Praktis:Anak, Remaja dan Keluarga. Jakarta:PT BPK Gunung Mulia.

Siska Eko Mawarsih. 2013. Pengaruh Perhatian Orang Tua dan Motivasi Belajar terhadap Presatsi Belajar Siswa SMA Negeri Jumapolo. JUPE UNS, Vol. 1. ( http://dglib.uns.ac.id/pengguna.php?mn=detail\&d_id=31505, diakses 21 Nopember 2013).

Sugiyono. 2007. Metode Penelitian Pendidikan. Bandung: Alfabeta. 2010. Metode Penelitian Pendidikan. Bandung: Alfabeta

Suharsimi Arikunto. 2002. Prosedur Penelitian Suatu Pendekatan Praktik. Jakarta: Rineka Cipta. 2005. Manajemen Penelitian. Jakarta: Rineka Cipta. . 2010. Prosedur Penelitian Suatu Pendekatan Praktik. Jakarta: Rineka Cipta.

Sumadi Suryabrata.2008.Psikologi Pendidikan.Jakarta:PT Raja Grafindo Persanda

Syaiful Bahri Djamarah. 2004. Pola Komunikasi Orang Tua dan Anak.Jakarta: Rineka Cipta

Taofiq. 2010. Penerapan Metode Pembelajaran Pemonstration dan Experiment pada Pembelajaran Pekerjaan Dasar Konstruksi Bangunan dalam Upaya Peningkatan Prestasi Belajar dan Keaktifan pada Peserta Didik Kelas X TGB Program Keahlian Bangunan di SMK Negeri 2 Surakarta.Skripsi tidak diterbitkan. Surakarta:Pendidikan Teknik Sipil/Bangunan Fakultas Keguruan dan Ilmu Pendidikan Universitas Sebelas Maret.

Wahjoedi. 2011. Bunga Rampai Hasil Penelitian Olahraga Tahun 2009. Jakarta:

Asisten Deputi Penerapan IPTEK Keolahragaan, Deputi Bidang Peningkatan Prestasi Olahraga, Kemenpora R.I

Wharton, Steve. 2005. How to stop that bully,Menghentikan si Tukang Teror. Yogyakarta: Kanisius

Yoli Hemdi. 2010. Kenakalan Teman Bullying. Jakarta: Bilingual 